\title{
Produção de alface em NFT e Floating aproveitando água salobra e o rejeito da dessalinização ${ }^{1}$
}

\author{
Lettuce production under NFT and Floating using brackish groundwater and the \\ reject from its desalination
}

\author{
Alexandre Nascimento dos Santos ${ }^{2 *}$, Ênio Farias de França e Silva ${ }^{3}$, Tales Miler Soares ${ }^{4}$, Raquele Mendes Lira \\ Dantas $^{5}$ e Manassés Mesquita da Silva ${ }^{6}$
}

\begin{abstract}
Resumo - Plantas de alface cv. Elba foram cultivadas em dois sistemas hidropônicos, Floating e NFT, com o objetivo de avaliar três tipos de água: a água salobra natural $\left(2,47 \mathrm{dS} \mathrm{m}^{-1}\right)$ obtida a partir de um poço profundo; água doce $\left(0,11 \mathrm{dS} \mathrm{m}^{-1}\right)$ produzido por dessalinização por osmose inversa, e o rejeito salino $\left(5,15 \mathrm{dS} \mathrm{m}^{-1}\right)$, um efluente do processo de dessalinização. Estas águas foram combinadas em seis tratamentos resultantes da sua utilização alternada para preparar a solução nutritiva (SN) e/ou substituir as perdas por evapotranspiração (ETc). O experimento foi conduzido em casa de vegetação na região semiárida de Pernambuco, utilizando 48 unidades experimentais em blocos casualizados em esquema fatorial $6 \times 2$ com quatro repetições. $\mathrm{O}$ rendimento da alface (massa de matéria fresca) foi maior nas condições do Floating. O uso exclusivo da água do poço profundo e do rejeito de dessalinizadores diminuiu 22,7 e 39,6\% a produção de alface, respectivamente. Para uma melhor combinação de águas doces e salobras, o uso de água salobra para repor a perda por ETc pode aumentar a produção de alface em relação ao uso dessas águas para preparar a SN, estes resultados foram registrados para a água do poço profundo e o rejeito.
\end{abstract}

Palavras-chave - Recursos hídricos. Água salobra. Semiárido.

\begin{abstract}
Plants of lettuce cv. Elba were grown under two hydroponic systems, Floating and NFT, aiming to evaluate three water resources: natural brackish water $\left(2,47 \mathrm{dS} \mathrm{m}^{-1}\right)$ obtained from a deep well; fresh water $\left(0,11 \mathrm{dS} \mathrm{m}^{-1}\right)$ produced by reverse osmosis desalination; and reject brine $\left(5,15 \mathrm{dS} \mathrm{m}^{-1}\right)$, a wastewater from desalination process. These waters were combined in six treatments resulted from their alternated use to prepare nutrient solution (NS) and/or replace the evapotranspiration loss (ETc). The experiment was carried out under a greenhouse condition in the semiarid region of Pernambuco State, Brazil; 48 experimental units were used for both hydroponic systems. The lettuce yield (shoot fresh matter) was higher under Floating conditions. The single use of deep well water and reject brine decreased 22.7 and $39.6 \%$ the lettuce yield, respectively. For a better combination of fresh and brackish waters, the use of brackish water to replace ETc loss may increase the lettuce yield in comparison to use these waters to prepare the NS; this result was registered for deep well water and reject.
\end{abstract}

Key words - Water resources. Brackish water. Semiarid.

\footnotetext{
* Autor para correspondência

${ }^{1}$ Recebido para publicação em 31/08/2010; aprovado em 31/01/2011

Trabalho submetido e selecionado no primeiro Simpósio Brasileiro de Salinidade realizado de 12-15/10/2010 em Fortaleza, Ceará, Brasil; A pesquisa teve o financiamento e a colaboração da FACEPE, INCTSal/CNPq e UFRPE

${ }^{2}$ Programa de Pós-Graduação em Engenharia Agrícola, UFRPE, Rua Dom Manoel de Medeiros, s/n, Dois Irmãos, Recife-PE, Brasil, 52.171-900, alexandrens14@yahoo.com.br

${ }^{3}$ Departamento de Tecnologia Rural/UFRPE, Recife-PE, Brasil, enio.silva@dtr.ufrpe.br

${ }^{4}$ Centro de Ciências Agrárias, Ambientais e Biológicas/UFRB, Cruz das Almas-BA, Brasil, talesmiler@gmail.com

${ }_{5}^{5}$ Programa de Pós-Graduação em Engenharia Agrícola, UFRPE, Recife-PE, Brasil, raquelelira@gmail.com

${ }^{6}$ Departamento de Tecnologia Rural/UFRPE, Recife-PE, Brasil, manasses@dtr.ufrpe.br
} 


\section{Introdução}

A utilização de águas subterrâneas de poços tubulares é uma alternativa ao abastecimento d'água das comunidades rurais do Semiárido do Nordeste brasileiro (ANDRADE JÚNIOR et al., 2006; MEDEIROS et al., 2003). Esses poços quando perfurados em região do embasamento cristalino geralmente possuem baixas vazões e têm altos teores de sais dissolvidos (COSTA et al., 2006; SILVA JÚNIOR et al., 1999; COSTA, 1995), podendo tornar essas águas inviáveis ao consumo humano e para a agricultura. Seu uso agrícola pode oferecer riscos ao meio ambiente, promovendo a salinização dos solos e redução da produção agrícola (ALENCAR et al., 2003; BELTRAN, 1999; FREIRE et al., 2003; GARCIA et al., 2008; PORTO et al., 2001).

Para melhoria dessas águas tem-se utilizado a técnica da osmose reversa, a qual, por um processo de filtração físico-químico, dessaliniza parte da água, separando-a dos sais, tornando-a própria ao consumo humano. Porém, o processo de dessalinização gera também um rejeito (40 a $60 \%$ da água processada) ainda mais salino que a água captada do poço. $O$ descarte inadequado desse rejeito poderá trazer impactos ambientais severos. Quase na totalidade dos casos o rejeito produzido nesse processo não vem recebendo qualquer tratamento, mas está sendo despejado no solo e nos cursos d'águas, propiciando alto acúmulo de sais nesses ambientes (PORTO et al., 2001; SOARES et al., 2006). Contudo, torna-se necessário o estudo de técnicas e manejos que visem a inclusão desta água residuária na cadeia produtiva, dando importância social e econômica a todos os tipos de água do processo de dessalinização.

Nesse sentido, o cultivo hidropônico usando água salobra e o rejeito da dessalinização vem sendo utilizado em pesquisas com alguns resultados exitosos (DIAS et al., 2010, PAULUS et al., 2010; SANTOS et al., 2010, SOARES et al., 2010, SOARES et al., 2007).

No sistema hidropônico de cultivo diferentes técnicas são utilizadas quanto a forma de aplicação de solução nutritiva, podendo estas técnicas influenciar na disponibilidade de água e nutrientes às plantas. A técnica do NFT (Técnica do fluxo laminar de nutrientes) é uma das técnicas desse sistema de cultivo que consiste na passagem de uma lâmina intermitente de solução nutritiva por um leito contendo as plantas. O ambiente interno desse leito pode influenciar a produção em função do material que o constitui e do intervalo entre as irrigações (MATTOS et al., 2001; ZANELLA et al., 2008). Já o Floating, outra técnica utilizada, também conhecida como DFT (deep film techinique), forma uma lâmina profunda (5 a $20 \mathrm{~cm})$, onde as raízes das plantas ficam submersas continuamente na solução nutritiva e suportadas por um sistema flutuante, sendo esta solução renovada ou aerada frequentemente ao longo do cultivo. Essa diferença na aplicação da solução pode promover diferentes respostas quanto ao rendimento das culturas, como demonstrado por Fernandes et al. (2004) que compararam o rendimento da cultura do manjericão (variedades 'Folha Estreita' e 'Folha Larga') cultivada em sistema hidropônico Floating e em substrato. Os autores observaram que o Floating possibilitou maior produtividade média da cultura do manjericão, cerca de $44 \%$ mais massa verde, comparada ao cultivo em substrato, ambos irrigados com a mesma solução nutritiva.

Com isso, o objetivo do presente trabalho foi: avaliar o rendimento da cultura da alface cv. 'Elba' produzida em sistema hidropônico NFT e Floating quando submetida às diferentes águas do processo de dessalinização.

\section{Material e métodos}

O experimento foi conduzido em casa de vegetação, no período de 27/07/2009 a 21/09/2009, na unidade piloto de uso da água subterrânea e do rejeito de dessalinizadores da Universidade Federal Rural de Pernambuco - UFRPE, localizada na comunidade Poço do Boi, Município de Ibimirim, PE. Ibimirim tem clima classificado como B'Swh', semiárido muito quente tipo estepe (classificação de Köppen), estando localizada no Sertão de Pernambuco, nas coordenadas geográficas $8^{\circ} 32^{\prime} 15^{\prime \prime}$ de latitude Sul, $37^{\circ} 41^{\prime} 30^{\prime \prime}$ de longitude Oeste, e a uma altitude $431 \mathrm{~m}$.

Diariamente se registravam as temperaturas máxima e mínima e a umidade relativa do ar para um período de 24 horas utilizando-se termohigrômetro. O aparelho foi protegido em um abrigo e instalado no centro da casa de vegetação a uma altura de $1,50 \mathrm{~m}$ em relação à superfície do solo.

Na Figura 1 se encontra a variação da temperatura e umidade relativa do ar, medida a $1,5 \mathrm{~m}$ de altura, e a variação da temperatura da solução nutritiva, medida no interior do reservatório. As temperaturas médias diárias do ar no interior da casa de vegetação registradas durante o período de estudo, variaram de 14,7 a $51,4{ }^{\circ} \mathrm{C}$ para as temperaturas mínimas e máximas, respectivamente. Em relação à umidade relativa do ar as médias no período de cultivo variaram de $13 \%$ a $99 \%$ (FIG. 1). Os valores registrados de temperatura do ar (FIG. 1) ultrapassaram as recomendações $\left(15\right.$ a $25^{\circ} \mathrm{C}$ ) para alface (MARTINEZ, 2006), à semelhança da umidade relativa do ar cujos valores registrados estiveram fora da faixa recomendada como ideal, 60 a 80\% (MARTINEZ, 2006).

A temperatura da solução foi medida às $15 \mathrm{~h} \mathrm{em}$ um reservatório de uma bancada localizada no centro da casa de vegetação. Escolheu-se este horário com base 
em um acompanhamento prévio da temperatura entre 6 e $18 \mathrm{~h}$ durante seis dias, buscando-se o momento em que a solução atingia sua maior temperatura.

As temperaturas da solução nutritiva tomadas às $15 \mathrm{~h}$ (FIG. 1) variaram entre 30 e $38^{\circ} \mathrm{C}$, sendo que no ciclo de cultivo a média da temperatura neste horário foi de $34{ }^{\circ} \mathrm{C}$. Registrou-se, portanto, que a temperatura da solução chegou a ultrapassar o limite indicado por Alberoni (1998), qual seja: $30{ }^{\circ} \mathrm{C}$. O mesmo autor recomenda como ideais as temperaturas na faixa de 18 a $24{ }^{\circ} \mathrm{C}$ para períodos quentes e de 10 a $16{ }^{\circ} \mathrm{C}$ para períodos frios.

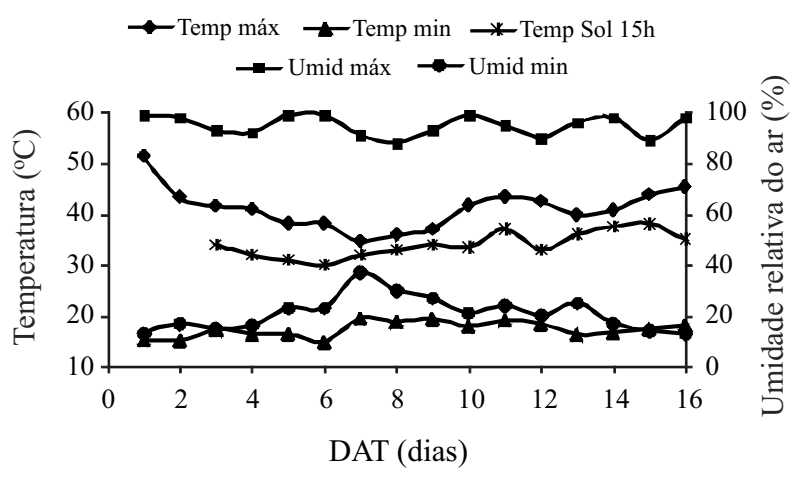

Figura 1 - Umidade relativa do ar e temperaturas do ar e da solução nutritiva ao longo do ciclo de cultivo. Temp max: temperatura máxima do ar; Temp min: temperatura mínima do ar; Temp Sol 15h: temperatura da solução nutritiva às 15:00 h; Umid max: umidade relativa do ar máxima; Umid min: umidade relativa do ar mínima

A água utilizada para o produção hidropônica foi proveniente de uma fonte de água subterrânea salobra captada de um poço tubular e posteriormente processada em sistema de dessalinização de água por osmose reversa. O rendimento do sistema de dessalinização usado no presente estudo está apresentado na Tabela 1. Durante o experimento, a água do poço apresentou uma condutividade elétrica de 2,47 $\mathrm{dS} \mathrm{m}^{-1}$, enquanto a água dessalinizada e a água de rejeito da dessalinização apresentaram CE de 0,11 e $5,15 \mathrm{dS} \mathrm{m}^{-1}$, respectivamente.

O delineamento experimental utilizado foi em blocos casualizados, em esquema fatorial: com seis combinações de tipos de água, a partir da água salobra natural (poço tubular profundo), água dessalinizada e água residuária da dessalinização (rejeito) (TAB. 2), em interação com dois sistemas de cultivo hidropônico (NFT e Floating), totalizando 12 tratamentos que foram aleatorizados em quatro repetições. A combinação de águas doce e salobra é interessante para se definir estratégias de manejo quando se dispõe dessas duas fontes de água; nesse caso, têmse três subgrupos de contrastes de interesse: subgrupo de tratamentos no qual se avaliou o uso exclusivo de um mesmo tipo de água (T1 x T4 x T6); subgrupo no qual se avaliou a combinação da água salobra natural (poço) com a água doce (T2 x T3 x T4); subgrupo para avaliação dos tipos de água empregada apenas no preparo da solução nutritiva, empregando-se água dessalinizada na reposição da evapotranspiração (T1 x T3 x T5).

No sistema NFT foram cultivadas quatro plantas, sendo as duas plantas centrais consideradas úteis. Já no sistema Floating havia uma única planta por parcela.

A unidade experimental do sistema NFT foi composta por uma bancada hidropônica individual semelhante à descrita por Soares et al. (2009). Aproveitando a mesma estrutura do sistema NFT, adaptou-se o sistema Floating. Nesse caso, tinha-se associadas uma parcela NFT a uma parcela Floating, ambas submetidas à um mesmo tratamento e à mesma frequência de irrigação.

A parcela do sistema Floating consistiu de um vaso (capacidade para $4 \mathrm{~L}$ ) conectado ao sistema de injeção de solução nutritiva do sistema NFT; assim, a solução nutritiva do NFT era injetada no vaso do Floating, sendo o excesso drenado mediante um tubo extravasador, instalado a $1 \mathrm{~cm}$ da borda do vaso e cuja função também era o controle do volume de solução por vaso (FIG. 2).

Tabela 1 - Rendimento do sistema de dessalinização

\begin{tabular}{cccc}
\hline \multirow{2}{*}{ Data das Leituras } & \multicolumn{2}{c}{ Vazão $\left(\mathrm{L} \mathrm{h}^{-1}\right)$} & Rendimento relativo de água dessalinizada $(\%)$ \\
\cline { 2 - 3 } & Água dessalinizada & Rejeito & 50,0 \\
\hline $28 / 06 / 2008$ & 1216,3 & 1216,3 & 51,2 \\
$02 / 07 / 2008$ & 1230,1 & 1172,0 & 50,3 \\
$04 / 09 / 2008$ & 1155,1 & 1142,9 & 49,8 \\
$25 / 08 / 2009$ & 1220,0 & 1229,0 & \\
\hline
\end{tabular}


Tabela 2 - Descrição das combinações de tipos de águas empregadas no cultivo da alface

\begin{tabular}{ccc}
\hline \multirow{2}{*}{ Tratamento } & \multicolumn{2}{c}{ Tipo de água usada para } \\
\cline { 2 - 3 } & Preparo da Solução Nutritiva & Reposição da Evapotranspiração \\
\hline $\mathrm{T} 1_{\text {dessdes }}$ & Desssalinizada & Desssalinizada \\
$\mathrm{T} 2_{\text {des/ap }}$ & Desssalinizada & Água do poço \\
$\mathrm{T} 3_{\text {ap/des }}$ & Água do poço & Desssalinizada \\
$\mathrm{T} 4_{\text {ap/ap }}$ & Água do poço & Água do poço \\
$\mathrm{T} 5_{\text {rejdes }}$ & Rejeito & Desssalinizada \\
$\mathrm{T} 6_{\text {reirei }}$ & Rejeito & Rejeito \\
\hline
\end{tabular}

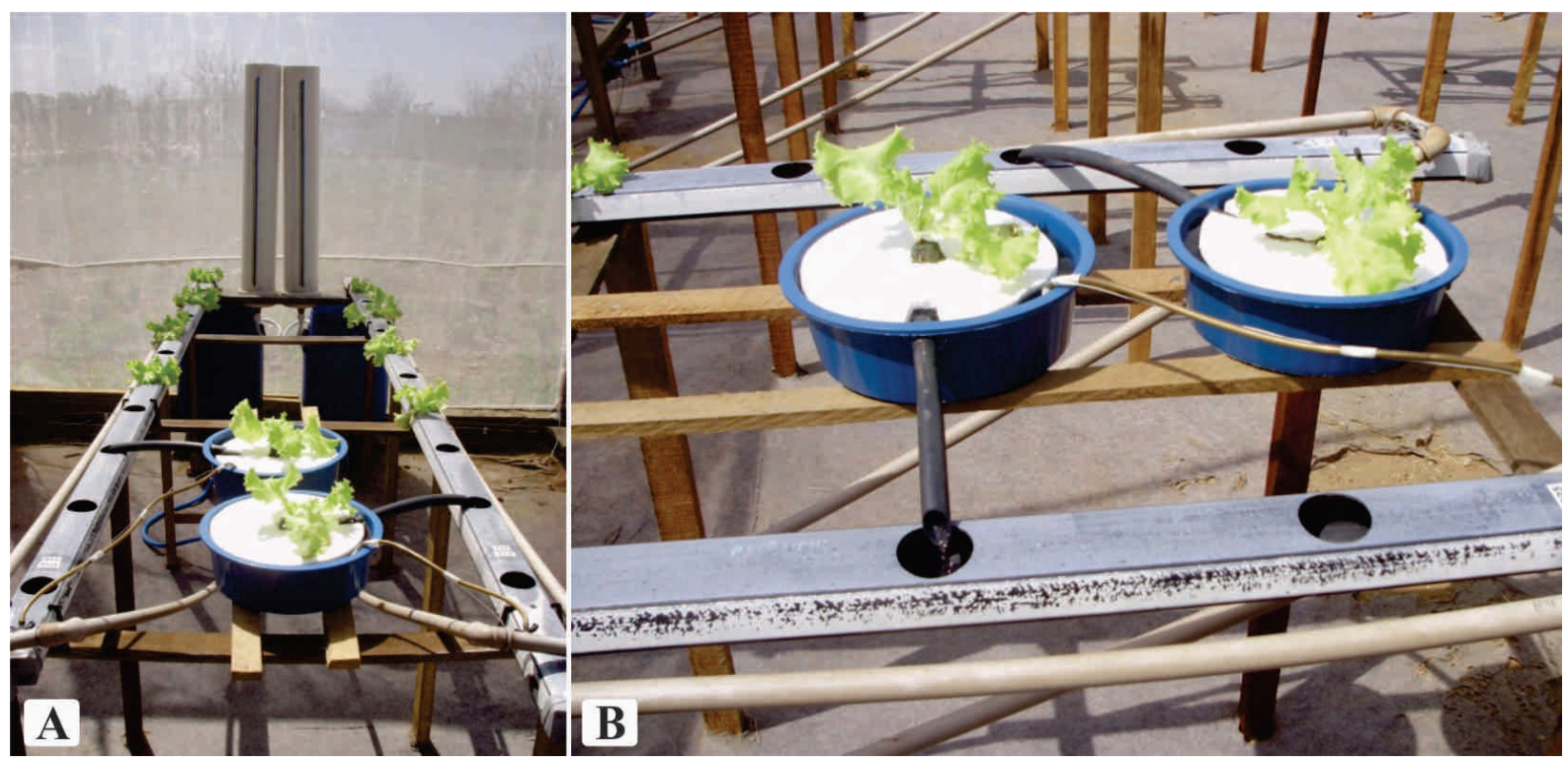

Figura 2 - Unidade experimental de sistema hidropônico NFT (A) e Floating (B)

No sistema NFT, quatro mudas, produzidas em espuma fenólica cúbica $(2 \times 2 \times 2 \mathrm{~cm})$ foram dispostas diretamente na calha de cultivo, constituindo-se uma parcela. No sistema Floating, uma muda, também produzida em espuma fenólica, foi afixada a uma placa de isopor, de formato circular, com diâmetro inferior à abertura do vaso em $1 \mathrm{~cm}$. A solução nutritiva injetada no vaso do Floating drenava deste para dentro da calha do NFT, ou seja, constituiu-se um sistema fechado com frequente renovação da solução nutritiva.

Os eventos de circulação da solução nutritiva durante o dia se deram com intervalos de 15 minutos, tendo duração de 15 minutos (ZANELLA et al., 2008); pela noite, os intervalos entre irrigações foram de duas horas, com duração de 15 minutos.

A solução nutritiva foi monitorada a cada dois dias, registrando-se os valores de $\mathrm{pH}$, condutividade elétrica
$\left(\mathrm{CE}_{\mathrm{sol}}\right)$ e temperatura. O pH e a $\mathrm{CE}_{\mathrm{sol}}$ foram medidos sempre pela manhã, para que os valores medidos representassem as variações de um período de $24 \mathrm{~h}$.

As correções do $\mathrm{pH}$ das águas foram realizados no momento do preparo da solução nutritiva, antes da adição dos fertilizantes, bem como de dois em dois dias ao longo do experimento. Flutuações de $\mathrm{pH}$ foram observadas, sendo maior nas soluções nutritiva que usavam água salobra do poço e o rejeito do dessalinizador, porém, eram controladas dentro da faixa definida como ideal (FIG. 3A). As correções de $\mathrm{pH}$ foram feitas mediante adição de $\mathrm{KOH}$ ou $\mathrm{HNO}_{3}$ sempre que se extrapolavam os limites de 5 e 7 (FURLANI et al., 1999).

Com relação à CE se registraram, conforme previsto, aumentos nos níveis de salinidade da solução nutritiva ao longo do ciclo de cultivo para os tratamentos que utilizaram água salobra na reposição da lâmina evapotranspirada, pois 
havia adição contínua de sais; já nos tratamentos em que se fazia reposição com água dessalinizada, a CE manteve-se quase que constante (FIG. 3B).
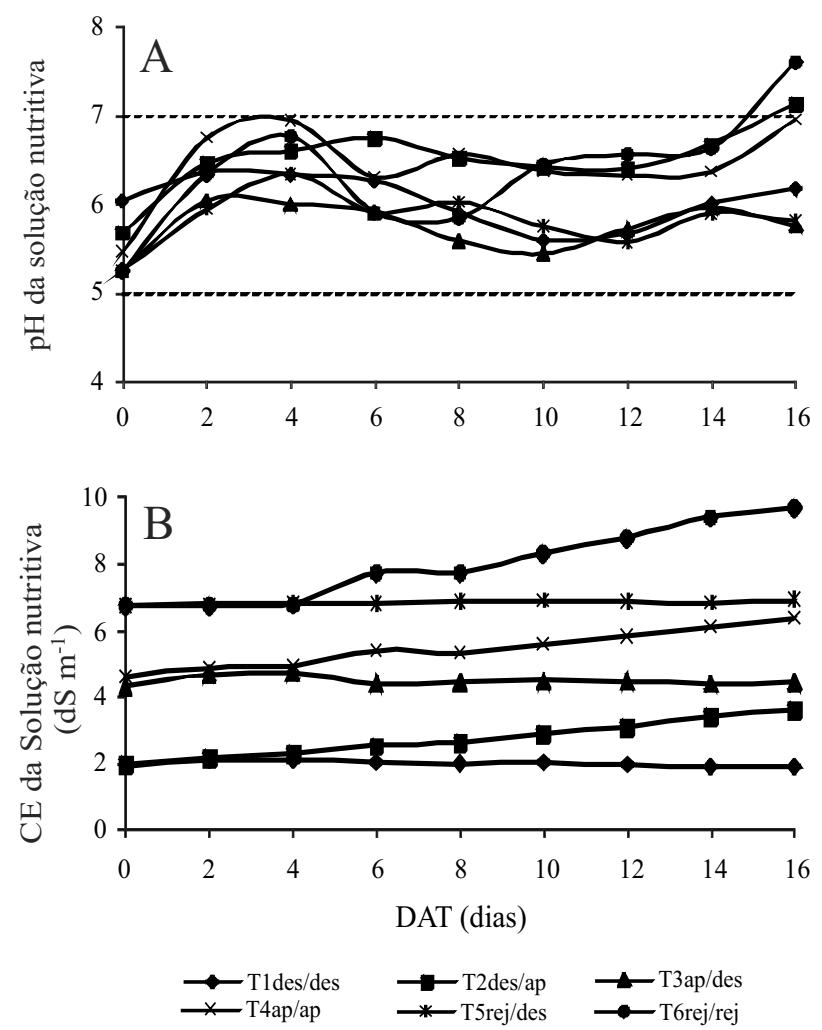

Figura 3 - pH (A) e Condutividade elétrica (B) da solução nutritiva ao longo do ciclo de cultivo

Sementes de alface cv. 'Elba' foram semeadas em placas de espuma fenólicas e após a germinação foram dispostas em berçário até a época do transplantio; durante a fase de berçário as mudas foram irrigadas com solução nutritiva preparada com água dessalinizada $\left(\mathrm{CE}_{\mathrm{sol}}=1,9 \mathrm{dS} \mathrm{m}^{-1}\right)$. A solução nutritiva utilizada nesse estudo foi a indica por Furlani (1999) para o cultivo da alface. As mudas de alface foram transplantadas para as unidades experimentais, momento em que se iniciaram os tratamentos. O ciclo de cultivo foi de 56 dias após a semeadura, sendo o período de submissão aos tratamentos os últimos 16 dias.

Para avaliação do rendimento da cultura de alface cultivada, analisaram-se as seguintes variáveis: diâmetro de cabeça (DC) e massa de matéria fresca da parte aérea (MFPA), determinadas no dia da colheita. As massas de matéria seca da parte aérea (MSPA) e da raiz (MSR) foram outras variáveis analisadas, sendo determinadas após secagem em estufa a $65^{\circ} \mathrm{C}$ até atingir massa constante. As variáveis MFPA, MSPA e MRS foram determinadas com o auxílio de uma balança de precisão $(0,01 \mathrm{~g})$. Também se avaliou o teor de água $(\Theta)$ no tecido da parte aérea, sendo determinado através da equação 1 .

$\theta(\%)=\left(\frac{\text { MFPA }- \text { MSPA }}{\text { MFPA }}\right) \times 100$

Os dados foram submetidos à análise de variância, sendo as variáveis com efeitos significativos submetidas à comparação de média, utilizando-se o teste de Tukey ao nível de 5\% de significância.

\section{Resultados e discussão}

O tipo de sistema de cultivo influenciou significativamente as variáveis de crescimento e produção da alface 'Elba' cultivada em hidroponia (TAB. 3). No sistema Floating o acúmulo de massas de matéria fresca e seca da parte aérea, além do diâmetro do caule e do teor de água na parte aérea da planta, foram maiores que no sistema NFT. Por outro lado, no NFT o sistema radicular se desenvolveu mais em termos de produção de massa de matéria seca (TAB. 4). Fernandes et al. (2004) que compararam o rendimento da cultura do manjericão (variedades 'Folha Estreita' e 'Folha Larga') sendo cultivada em sistema hidropônico Floating e em substrato, observaram que o Floating possibilitou maior produtividade média da cultura do manjericão, cerca de $44 \%$ mais massa verde, comparada ao cultivo em substrato, ambos irrigados com a mesma solução nutritiva.

A superioridade na produção da alface no sistema Floating pode ser atribuída à característica do sistema, no qual as raízes estão sempre providas com solução nutritiva oxigenada. No sistema NFT, apesar da alta frequência de irrigação, comparada à agricultura irrigada convencional no solo, tem-se sim um período de restrição hídrica para as plantas que pode se constituir numa fonte de estresse para as raízes, com repercussão na transpiração e absorção de íons. Zanella et al. (2008) comprovaram que o aumento no intervalo entre as irrigações tem influência na produção de alface, os autores concluíram que quanto menor o intervalo entre as irrigações maior é a produção.

Apesar de não se monitorar a temperatura da solução nutritiva no ambiente radicular, dentro dos perfis hidropônicos no NFT e dos vasos no Floating, uma das possíveis explicações para os resultados acima diz respeito ao estresse térmico ao qual as raízes confinadas no sistema NFT foram submetidas entre eventos sucessivos de irrigação; no sistema Floating, 
a presença da água deve atenuar as temperaturas da solução nutritiva entre as irrigações. Mattos et al. (2001), estudando a temperatura no interior das canaletas no cultivo hidropônico de alface no sistema NFT cobertas com diferentes materiais, observaram que o material que proporcionou a menor temperatura obteve a maior produção de alface.

Em relação ao uso exclusivo dos diferentes tipos de água envolvidos no processo da dessalinização (TAB. 5), observou-se maior produção da alface, em termos de massa de matéria fresca da parte aérea, quando submetida ao uso de água dessalinizada; o uso de água do poço proporcionou produção significativamente menor que o uso de água dessalinizada (T1 x T4), mas produção significativamente superior à água do rejeito (T4 x T6). Isso revela um gradiente significativo de perdas de produção para os três tipos de água à medida que se aumenta a salinidade da água. Esse comportamento também foi observado por outros autores estudando o uso de água salobra empregada tanto no preparo da solução nutritiva quanto na reposição da evapotranspiração na produção de alface em sistema hidropônico NFT eles observaram um decréscimo na produção da alface com o aumento da salinidade da água usada no processo (PAULUS et al., 2010; SANTOS et al., 2010; SOARES et al., 2010; SOARES et al., 2007).
Esse resultado foi esperado e permitiu calcular os seguintes níveis de redução percentual da produção, em relação à testemunha, para o emprego de águas do poço (T1 x T4) e de rejeito (T1 x T6), respectivamente: 22,67 e $39,58 \%$. Em relação à massa de matéria seca da parte aérea e o diâmetro do caule não foi registrada diferença significativa entre as águas do poço e de rejeito. A massa de matéria seca das raízes e o teor de água da parte aérea não foram prejudicados pelo uso exclusivo das águas dessalinizada, de poço e de rejeito.

Outro contraste de interesse diz respeito ao tipo de estratégia de uso de água doce em combinação com águas salobras. Quando se considera a água salobra do poço (T2 x T4), foi mais produtivo empregá-la na reposição das perdas por evapotranspiração (T2), em relação ao seu uso no preparo da solução nutritiva (T4). Esses resultados estão de acordo com os obtidos por Soares et al. (2010), trabalhando com combinações de água doce e salobra no cultivo hidropônico de alface em NFT, os autores concluíram que quando as águas salobras foram usadas apenas na reposição da evapotranspiração, o porte das plantas foi visualmente semelhante ao das plantas submetidas ao tratamento controle (solução nutritiva preparada com água doce e reposição da evapotranspiração com água doce). Isso pode ser explicado pelo incremento de íons essenciais contidos na água do poço, promovendo um consumo de luxo às plantas.

Tabela 3 - Análise de variância das variáveis estudadas

\begin{tabular}{ccccccc}
\hline \multirow{2}{*}{ Fonte de variação } & \multirow{2}{*}{ GL } & \multicolumn{3}{c}{---------------- Quadrado médio ---------------- } \\
\cline { 3 - 7 } & & MFPA & MSPA & MSR & $\theta$ & DC \\
\hline Blocos & 3 & $235,01^{\text {ns }}$ & $0,26^{\text {ns }}$ & $0,29^{\text {ns }}$ & $1,66^{\text {ns }}$ & $5,78^{\text {ns }}$ \\
Sistema de cultivo (SC) & 1 & $7781,47^{* *}$ & $2,20^{\text {ns }}$ & $0,49^{\text {ns }}$ & $21,68^{* *}$ & $34,59^{* *}$ \\
Combinação de água (CA) & 5 & $4366,21^{* *}$ & $22,24^{* *}$ & $0,21^{\text {ns }}$ & $0,64^{\text {ns }}$ & $18,29^{* *}$ \\
SC x CA & 5 & $96,00^{\text {ns }}$ & $1,74^{\text {ns }}$ & $0,02^{\text {ns }}$ & $1,46^{\text {ns }}$ & $1,34^{\text {ns }}$ \\
Erro & 33 & 176,28 & 1,65 & 0,12 & 0,89 & 3,14 \\
\hline CV (\%) & & 12,44 & 15,90 & 17,05 & 1,02 & 6,32 \\
\hline
\end{tabular}

** $\mathrm{e}^{\text {ns }}$ - Significativo a $1 \%$ e não significativo, respectivamente

Tabela 4 - Análise de comparação de médias das variáveis estudadas para os sistemas de cultivo

\begin{tabular}{|c|c|c|c|c|c|}
\hline \multirow{2}{*}{ Sistema de cultivo } & MFPA & MSPA & MSR & \multirow{2}{*}{$\begin{array}{c} \\
-----\% \text {----- }\end{array}$} & \multirow{2}{*}{ 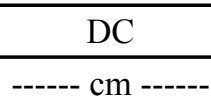 } \\
\hline & \multicolumn{3}{|c|}{ 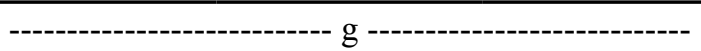 } & & \\
\hline NFT & $94,85 \mathrm{~b}$ & $7,87 \mathrm{a}$ & $2,14 \mathrm{a}$ & $91,65 \mathrm{~b}$ & $27,28 \mathrm{~b}$ \\
\hline Floating & $121,90 \mathrm{a}$ & $8,35 \mathrm{a}$ & $1,90 \mathrm{~b}$ & $93,09 \mathrm{a}$ & 29,06 a \\
\hline DMS & 8,69 & 0,79 & 0,24 & 0,63 & 1,19 \\
\hline C.V. & $12,7 \%$ & $15,2 \%$ & $18,26 \%$ & $1,06 \%$ & $5,59 \%$ \\
\hline
\end{tabular}

Letras diferentes na mesma coluna indicam diferenças entre as médias ao nível de 5\%; DMS = diferença mínima significativa; C.V. = coeficiente de variação 
Tabela 5 - Análise de comparação de médias das variáveis estudadas para as combinações de água

\begin{tabular}{|c|c|c|c|c|c|}
\hline \multirow{2}{*}{ Combinação de água } & MFPA & MSPA & MSR & $\Theta$ & $\mathrm{DC}$ \\
\hline & \multicolumn{3}{|c|}{ - } & ------ \% ------ & ----- cm ----- \\
\hline $\mathrm{T} 1_{\mathrm{des} / \mathrm{des}}$ & $137,45 \mathrm{a}$ & $10,73 \mathrm{a}$ & $2,12 \mathrm{a}$ & $92,07 \mathrm{a}$ & $29,43 \mathrm{ab}$ \\
\hline $\mathrm{T} 2_{\text {des/ap }}$ & $141,02 \mathrm{a}$ & $10,08 \mathrm{a}$ & $2,03 \mathrm{a}$ & $92,76 \mathrm{a}$ & $30,70 \mathrm{a}$ \\
\hline $\mathrm{T} 3_{\mathrm{ap} / \mathrm{des}}$ & $104,71 \mathrm{bc}$ & $7,98 \mathrm{~b}$ & $2,16 \mathrm{a}$ & $92,26 \mathrm{a}$ & $28,50 \mathrm{abc}$ \\
\hline $\mathrm{T} 4_{\mathrm{ap} / \mathrm{ap}}$ & $106,29 \mathrm{~b}$ & $7,81 \mathrm{~b}$ & $2,16 \mathrm{a}$ & 92,65 a & $28,06 \mathrm{abc}$ \\
\hline $\mathrm{T}_{\text {rej/des }}$ & $77,71 \mathrm{~d}$ & $6,30 \mathrm{~b}$ & $1,75 \mathrm{a}$ & $91,74 \mathrm{a}$ & $25,93 \mathrm{c}$ \\
\hline T6 $6_{\text {rei/rei }}$ & $83,04 \mathrm{~cd}$ & $6,19 \mathrm{~b}$ & $1,99 \mathrm{a}$ & $92,27 \mathrm{a}$ & $26,50 \mathrm{bc}$ \\
\hline DMS & 22,50 & 2,05 & 0,62 & 1,64 & 3,08 \\
\hline C.V. & $12,7 \%$ & $15,2 \%$ & $18,26 \%$ & $1,06 \%$ & $5,59 \%$ \\
\hline
\end{tabular}

Letras diferentes na mesma coluna indicam diferenças entre as médias ao nível de 5\%; DMS = diferença mínima significativa; C.V. = coeficiente de variação

Dias et al. (2010), em um experimento com melão cultivado em hidroponia de substrato utilizando diluições do rejeito de dessalinizadores no preparo da solução nutritiva, registraram efeito quadrático na altura das plantas de melão e atribuíram tal efeito ao incremento de íons específicos contidos no rejeito de dessalinizadores, sobretudo o cálcio e o magnésio, sendo esse efeito benéfico até um ponto de máxima da curva, quando o efeito osmótico se sobrepõe ao nutricional, causando toxidez de íons ou pela dificuldade de absorção de água pelas plantas. Santos et al. (2010), trabalhando com a água do mesmo poço usado no presente estudo, porém, em um período em que a água estava menos concentrada e apresentava CE de $1,7 \mathrm{dS} \mathrm{m}^{-1}$, registraram concentrações de cálcio e magnésio na ordem de 74,19 e $71,86 \mathrm{mg} \mathrm{L}^{-1}$, respectivamente, reforçando essa teoria.

Contrastando os tratamentos que combinam águas doce e salobra com tratamentos que empregam exclusivamente águas salobras, constatou-se que o uso de água doce na reposição da evapotranspiração, empregando-se as águas salobras no preparo da solução nutritiva não proporciona vantagem comparativa em relação ao uso exclusivo das águas de poço e de rejeito (T3 x T4; T5 x T6).

\section{Conclusões}

1. O sistema Floating de produção hidropônica proporcionou melhor rendimento produtivo no cultivo de alface cv. 'Elba' comparado ao cultivo em sistema NFT;
2. Quando se utilizar a água natural salobra do poço para o preparo da solução nutritiva, a mesma água pode substituir a água doce na reposição da lâmina evapotranspirada na produção hidropônica de alface cv. 'Elba' sem perdas de rendimento. A mesma observação foi válida para uso da água de rejeito;

3. Ao se combinar água doce com a água do poço, alternando-as no preparo da solução nutritiva e na reposição da lâmina evapotranspirada, obteve-se maior rendimento da alface quando a água do poço foi usada na reposição da lâmina evapotranspirada;

4. O uso exclusivo das água salobra do poço e do rejeito de sua dessalinização proporcionaram perdas de 22,7 e $39,6 \%$, em relação ao uso exclusivo de água dessalinizada.

\section{Agradecimentos}

Os autores agradecem à Universidade Federal Rural de Pernambuco - UFRPE, ao Instituto Nacional de Ciência e Tecnologia em Salinidade (INCTSal/CNPq) e à Fundação de Amparo à Ciência e Tecnologia do Estado de Pernambuco - FACEPE.

\section{Referências}

ALBERONI, R. B. Hidroponia. São Paulo: Nobel, 1998. 102p.

ALENCAR, R. D. et al. Crescimento de cultivares de melão amarelo irrigadas com água salina. Revista Brasileira de Engenharia Agrícola e Ambiental, v.7, n.2, p.221-226, 2003. 
ANDRADE JÚNIOR, A. S. et al. Uso e qualidade da água subterrânea para irrigação no semi-árido piauiense. Revista Brasileira de Engenharia Agrícola e Ambiental, v.10, n.4, p.873-880, 2006.

BELTRAN, J. M. Irrigation with saline water: Benefits and environmental impact. Agricultural Water Management, v.40, n.2, p.183-194, 1999.

COSTA, A. M. B. et al. Aspectos da salinização das águas do aqǘ́fero cristalino no estado do Rio Grande do Norte, Nordeste do Brasil. Águas Subterrâneas, v.20, n.1, p.67-82, 2006.

COSTA, W. D. Problemática da Água Subterrânea no Nordeste Brasileiro. Revista Águas Subterrânea, v.14, p.25-42, 1995.

DIAS, N. S. et al. Produção de melão rendilhado em sistema hidropônico com rejeito da dessalinização de água em solução nutritiva. Revista Brasileira de Engenharia Agrícola e Ambiental, v.14, n.7, p. 755-761, 2010.

FERNANDES, P. C. et al. Cultivo de manjericão em hidroponia e em diferentes substratos sob ambiente protegido. Horticultura Brasileira, Brasília, v.22, n.2, p.260-264, 2004.

FREIRE, M. B. G. S. et al. Estimativa do risco de sodificação de solos de Pernambuco pelo uso de águas salinas. Revista Brasileira Engenharia Agrícola e Ambiental, v.7, n.2, p.227-232, 2003.

FURLANI, P. R. et al. Cultivo hidropônico de plantas.1.ed. Campinas: IAC, 1999. 52p. Boletim técnico, 180.

GARCIA, G. O. et al. Alterações químicas de dois solos irrigados com água salina. Revista Ciência Agronômica, v.39, n.1, p.7-18, 2008.

MARTINEZ, H. E. P. Manual prático de hidroponia. Viçosa: Aprenda Fácil, 2006. 271p.

MATTOS, K. M. C. et al . Temperatura do ar no interior do canal de cultivo e crescimento da alface em função do material de cobertura da mesa de cultivo hidropônico - NFT. Bragantia, v. 60, n. 3, p. $253-260,2001$
MEDEIROS, J. F. et al. Caracterização das águas subterrâneas usadas para irrigação na área produtora de melão da Chapada do Apodi. Revista Brasileira de Engenharia Agrícola e Ambiental, v.7, n.3, p.469-472, 2003.

PAULUS, D. et al. Produção e indicadores fisiológicos de alface sob hidroponia com água salina. Horticultura Brasileira, v. 28, n.1, p.29-35, 2010

PORTO, E. R. et al. Uso do rejeito da dessalinização de água salobra para irrigação da erva-sal (Atriplexnummularia). Revista Brasileira de Engenharia Agrícola e Ambiental, v.5, n.1, p.111-114, 2001.

SANTOS, A. N. et al. A. Cultivo hidropônico de alface com água salobra subterrânea e rejeito da dessalinização em Ibimirim, PE. Revista Brasileira de Engenharia Agrícola e Ambiental, v.14, n.9, p.961-969. 2010.

SILVA JÚNIOR, L. G. A. et al. Composição química de águas do cristalino do nordeste brasileiro. Revista Brasileira de Engenharia Agrícola e Ambiental, v.3, n.1, p.11-17, 1999.

SOARES, TALES M. et al. Combinação de águas doce e salobra para produção de alface hidropônica. Revista Brasileira de Engenharia Agrícola e Ambiental, v.14, n.7, p. $705-714,2010$.

SOARES, T. M. et al. Experimental structure for evaluation of saline water use in lettuce hydroponic production. Irriga, v.14, n.1, p.102-114. 2009.

SOARES, T. M. et al. Produção de alface utilizando águas salinas em sistema hidropônico. Irriga, v.12, n.2, p.235-248, 2007.

SOARES, T. M. et al. Destinação de águas residuárias provenientes de dessalinizadores por osmose reversa. Revista Brasileira de Engenharia Agrícola e Ambiental, v.10, n.3, p.730-737, 2006.

ZANELLA, F. et al. Crescimento de alface hidropônica sob diferentes intervalos de irrigação. Ciência e Agrotecnologia, v.32, n.2, p.366-370, 2008. 